\title{
Polysulfide speciation and reactivity in Chromate-contaminated soil
}

\author{
Maria Chrysochoou ${ }^{\mathrm{a} *}$ and Chad P. Johnston ${ }^{\mathrm{a}}$ \\ ${ }^{a}$ Department of Civil and Environmental Engineering, University of Connecticut, Storrs, CT \\ 06269, USA \\ ${ }^{*}$ Corresponding author: tel: +18604863594 fax: +1 860486 2298, e-mail: \\ maria.chrysochoou@uconn.edu
}

\begin{abstract}
Calcium polysulfide (CPS) has been observed to maintain a reducing capacity for prolonged time periods when used to treat $\mathrm{Cr}(\mathrm{VI})$-contaminated soils. This study utilized bulk and micro-X-ray Absorption Near Edge Structure (XANES) spectroscopy to investigate sulfur speciation in soil samples treated with CPS in batch and column studies and to determine the source of the reducing potential. Bulk XANES spectra indicated the presence of two dominant sulfur species: elemental sulfur, which is the product of the sulfide-chromate redox reaction, and thiosulfate $\left(\mathrm{S}_{2} \mathrm{O}_{3}{ }^{2-}\right)$. Micro-XANES analyses confirmed these findings and showed that elemental sulfur precipitated as large particles, while thiosulfate was diffuse within the soil grains and thus available to react with chromate that leached from slowly dissolving $\mathrm{PbCrO}_{4}$. Micro-X-ray Fluorescence $(\mu \mathrm{XRF})$ analyses indicated a close association of $\mathrm{Pb}$ and thiosulfate, so that $\mathrm{PbS}_{2} \mathrm{O}_{3}$ is a likely sink for thiosulfate, accounting for up to $20 \%$ of the total $\mathrm{S}$ added. Sorption of thiosulfate on iron oxides below $\mathrm{pH} 8$ is a second retention mechanism for thiosulfate in the solid. Given that thiosulfate cannot reduce chromate but can reduce solid-bound Fe(III) under neutral $\mathrm{pH}$ conditions, it is hypothesized that ferrous iron production is an additional mechanism to maintain reductive conditions in CPS-treated soils.
\end{abstract}

Keywords: hexavalent chromium, polysulfide, thiosulfate, XANES, remediation 


\section{Introduction}

Chromium has been one of the top twenty contaminants on the Superfund Priority List of Hazardous Substances for the past 15 years. Treatment of toxic and hexavalent chromium $(\mathrm{Cr}(\mathrm{VI}))$ in soil and groundwater often relies on the reduction of mobile, anionic chromate $\left(\mathrm{CrO}_{4}{ }^{2-}\right)$ to non-toxic and immobile cationic trivalent chromium $(\mathrm{Cr}(\mathrm{III}))$, either chemically or biologically [1]. Calcium polysulfide (CPS) is a reductant that has been used in the field at several Cr-contaminated sites [2 - 4] and to treat Chromite Ore Processing Residue (COPR) [5] and contaminated soil for prolonged time periods $(>1 \mathrm{yr})[6-8]$. Field studies reported successful reduction at initial aqueous chromate concentrations ranging from $60 \mu \mathrm{g} / \mathrm{L}$ [9] to 200 mg/L [4]. COPR studies reported variable success with CPS reduction of solid-bound chromate. Specifically, Wazne et al. [7], Tinjum et al. [8], and Chrysochoou et al. [6] reported that chromate in COPR and soil appeared to be completely reduced using alkaline digestion and colorimetric analysis, contrary to the findings of complementary X-ray Absorption Spectroscopy and Diffraction analyses. However, the comparison of chemical and spectroscopic studies indicated that residual reductive capacity was presented both in CPS-treated COPR and contaminated soil for prolonged time periods ( $>1 \mathrm{yr})[6,7]$. This was not the case with COPR treatments based on sulfide, such as pyrite [10]. Thus, a difference in the reactivity and speciation of CPS compared to sulfide is required to explain the different behavior of these two reductants.

Recently, Chrysochoou and Ting [11] studied the kinetics of aqueous chromate reduction by CPS and the speciation of sulfur, with and without oxygen. Chromate reduction by CPS was observed to follow second-order kinetics and was significantly faster compared to sulfide that follows first-order kinetics. The influence of $\mathrm{pH}$ on oxidation kinetics was also observed to be different 
for sulfide and CPS, with sulfide showing a constant acceleration with decreasing $\mathrm{pH}$, while CPS showed a maximum at $\mathrm{pH} 7$ under aerobic conditions. This behavior was attributed to the preferred oxidation of CPS to form thiosulfate in the presence of oxygen, while sulfide forms sulfite and sulfate. Thiosulfate is produced according to the reaction [12]:

$\mathrm{S}_{\mathrm{x}}{ }^{2-}+3 / 2 \mathrm{O}_{2}->\mathrm{S}_{2} \mathrm{O}_{3}{ }^{2-}+(\mathrm{x}-2) \mathrm{S}^{0}(1)$

In contrast, the oxidation of sulfide through the reduction of chromate produces elemental sulfur according to the reaction:

$2 \mathrm{CrO}_{4}{ }^{2-}+3 \mathrm{CaS}_{5}+10 \mathrm{H}^{+} \leftrightarrow 2 \mathrm{Cr}(\mathrm{OH})_{3(\mathrm{~s})}+15 \mathrm{~S}_{(\mathrm{s})}+3 \mathrm{Ca}^{2+}+2 \mathrm{H}_{2} \mathrm{O}$

This study further explores the reductive capability and speciation of sulfur in a CPS-treated, chromate-contaminated soil, utilizing spectroscopic techniques in combination with a traditional column study.

\section{Materials and Methods}

\subsection{Soil samples and characterization}

Soil samples were obtained from a Cr-plating facility in Connecticut as described in Chrysochoou et al. [6]. Soil characteristics are shown in Table S1. Briefly, the soil is obtained from the surficial layer (top 5 feet) of an area adjacent to the facility that is highly contaminated with both $\mathrm{Cr}(11,900 \mathrm{mg} / \mathrm{kg})$ and $\mathrm{Pb}(13,200 \mathrm{mg} / \mathrm{kg})$. Approximately $40 \%$ of the $\mathrm{Cr}$ is present in the hexavalent form $(5,000 \mathrm{mg} / \mathrm{kg})$. The $\mathrm{Cr}$ source is the discharge of plating bath solutions from the facility into the soil, while the source of $\mathrm{Pb}$ is unknown. Prior to the initiation of this investigation the presence of $\mathrm{Pb}$ contamination in the soil was not suspected, but the very high 
concentrations point to anthropogenic contamination related to the facility activities. The two contaminants have been previously observed to be closely associated as $\mathrm{PbCrO}_{4}$ [6]. The stoichiometry between the two elements indicates that the $63.8 \mathrm{mmol} / \mathrm{kg}$ of $\mathrm{Pb}$ can be completely bound by the $96 \mathrm{mmol} / \mathrm{kg} \mathrm{Cr}(\mathrm{VI})$ present in the sample. Other co-contaminants are $\mathrm{Ni}$, which is present at higher than background concentrations $(440 \mathrm{mg} / \mathrm{kg})$. The soil is a glacial till with relatively high $\mathrm{Fe}$ content $(32,000 \mathrm{mg} / \mathrm{kg})$, which consists primarily of quartz and aluminosilicates such as feldspar and mica [6].

\subsection{Column studies}

Four columns were set up for this study, two control (denoted as CTRL-1 and CTRL-2) and two treated with approximately 0.5 pore volume (PV) $(25 \mathrm{~mL})$ of $29 \% \mathrm{CaS}_{5}$ solution (denoted as CPS-1 and CPS-2), which corresponded to $1 \mathrm{X}$ stoichiometric ratio for the chromate mass in the column. The column set up was identical to the column tests described in Chrysochoou et al. [13], and the description is also provided in the Supplementary Information. All columns were operated at $0.1 \mathrm{~mL} / \mathrm{min}$ injected from the bottom of the column; this flow rate corresponds to the upper limit of groundwater flow observed at the site [13]. The entire system was closed to the atmosphere by purging both the influent and the effluent bottles with nitrogen. A leaching solution that simulated groundwater at the site was used for all columns as described in Chrysochoou et al. [13] and Table S2. The CPS solution was injected into the treated columns at PV 6 and all columns were monitored for a total of 50 PVs. The effluents from the columns were regularly analyzed for $\mathrm{pH}$, redox potential, and $\mathrm{Cr}(\mathrm{VI})$ and total $\mathrm{Cr}$ concentrations. Selected measurements were taken for total $\mathrm{S}, \mathrm{Fe}, \mathrm{Mn}, \mathrm{Ni}$, and $\mathrm{Pb}$ concentrations. Upon termination, the columns were disassembled and characterized in three layers for total metals, total $\mathrm{Cr}(\mathrm{VI}), \mathrm{pH}$ and redox potential. All analytical methods are presented in the Supplemental Information. 


\subsection{Bulk XANES}

A separate batch study was set up to conduct bulk XANES analyses using the same soil sampled for the column studies. $30 \mathrm{~g}$ of soil was mixed with 3, 6, 12 and $24 \mathrm{~mL} 29 \%$ CPS solution (1X, $2 \mathrm{X}, 4 \mathrm{X}$ and $8 \mathrm{X}$ stoichiometric ratios, respectively), and nitrogen-purged deionized water was added to achieve a total volume of $30 \mathrm{~mL}$. The samples were mixed, purged with nitrogen, and sealed for 1 month prior to XANES analysis. The $2 \mathrm{X}$ stoichiometry was also tested at 0 days, 7 days, 2 months and 3 months of curing time. Control samples without CPS were prepared at 1 and 90 day time intervals. Triplicate samples were prepared for all dosages and curing times. XANES data were obtained at the Cr K-edge (5989 eV) and S K-edge (2472 eV) on beamline 43 at the Stanford Synchrotron Radiation Lightsource at the SLAC National Accelerator Laboratory; details are provided in Supplemental Information.

\subsection{Micro-X-Ray Analyses}

Two samples from the middle sections of the CTRL- 1 and CPS- 1 columns were prepared as 30 $\mu \mathrm{m}$ diamond-polished thin sections by Spectrum Petrographics (Vancouver, WA). Micro-XRF, $\mu \mathrm{XRD}$ and $\mu$ XANES measurements were performed on beamline 10.3.2 at the Advanced Light Source, Lawrence Berkeley National Lab. Micro-XRF elemental maps were acquired at 13.5 $\mathrm{keV}$ and $3.9 \mathrm{keV}$ incident energies with a beam size of $10 \mu \mathrm{m} \times 10 \mu \mathrm{m}$ and a counting time of 120 ms/pixel. Fluorescence counts were collected for $\mathrm{Si}, \mathrm{K}, \mathrm{Ca}, \mathrm{Ti}, \mathrm{Cr}, \mathrm{Mn}, \mathrm{Fe}, \mathrm{Ni}, \mathrm{Cu}, \mathrm{Zn}$ and $\mathrm{Pb}$ in the $13.5 \mathrm{keV}$ map and $\mathrm{S}$ in the $3.9 \mathrm{keV}$ map with a seven-element Ge solid-state detector. Chromium mapping was performed at incident energies of 5980,5993 and $6250 \mathrm{eV}$ to obtain the background, $\mathrm{Cr}(\mathrm{VI})$ and total $\mathrm{Cr}$ signals, respectively. Energy calibration was performed using a $\mathrm{Cr}$ foil $(5989 \mathrm{eV})$. The three maps were used to obtain maps for the $\mathrm{Cr}(\mathrm{VI})$ and $\mathrm{Cr}(\mathrm{III})$ signals 
using the chemical mapping analysis method described by Marcus [14] and employing $\mathrm{PbCrO}_{4}$ and $\mathrm{Cr}(\mathrm{OH})_{3}$ as XANES standards. Various spots of interest were selected for Cr K-edge $\mu$ XANES and $\mu$ XRD to probe $\mathrm{Cr}$ speciation. In addition, S XANES was performed on selected spots of a batch sample treated with 2X CPS for 2 months (details are discussed in Chrysochoou et al. [6]). Energy calibration for $\mathrm{S}$ was performed using $\mathrm{Na}_{2} \mathrm{~S}_{2} \mathrm{O}_{3}$.

\section{Results and Discussion}

\subsection{Column studies}

Figure 1 shows the $\mathrm{pH}$, redox potential, chromate (as $\mathrm{Cr}(\mathrm{VI})$ ) and total $\mathrm{S}$ in the column outflow. Under the conditions of the study, hexavalent chromium is either present as chromate $\left(\mathrm{CrO}_{4}{ }^{2-}\right)$ or $\mathrm{HCrO}_{4}{ }^{-}$below the pka of 6.5; for the remainder of the discussion, these species will be collectively referred to as $\mathrm{Cr}(\mathrm{VI})$. Figure $\mathrm{S} 1$ shows the concentrations of total $\mathrm{Cr}, \mathrm{Pb}, \mathrm{Fe}, \mathrm{Ni}$ and $\mathrm{Mn}$. The control columns maintained a $\mathrm{pH}$ of 5.5 and an Eh of $200 \mathrm{mV}$ throughout the monitoring period. The $\mathrm{Cr}(\mathrm{VI})$ concentration ranged from 0.3 to $0.45 \mathrm{mg} / \mathrm{L}$ during the first 6 PVs, presumably due to initial flushing of exchangeable chromate; after PV 6 the $\mathrm{Cr}(\mathrm{VI})$ concentration remained constant at approximately $0.16 \mathrm{mg} / \mathrm{L}$, indicating solubility control. Chrysochoou et al. [6] reported that $\mathrm{PbCrO}_{4}$ was the primary sink for chromate in this soil, which was also confirmed by the bulk and micro-XANES analyses. Modeling of a $\mathrm{Pb}-\mathrm{Cr}(\mathrm{VI})$ aqueous solution indicated that the solubility of $\mathrm{Cr}(\mathrm{VI})$ with respect to $\mathrm{PbCrO}_{4}$ at $\mathrm{pH} 5.5$ and $\mathrm{Pb}$ concentration of $0.3-0.5 \mathrm{mg} / \mathrm{L}$ is $0.05-0.13 \mathrm{mg} / \mathrm{L}$, which is quite close to the measured concentration. In the treated column, the $\mathrm{Cr}(\mathrm{VI})$ concentration decreased to non-detectable values $(<0.025 \mathrm{mg} / \mathrm{L})$ upon injection of CPS and remained below the detection limit for the 
remainder of the experiment (PV 50). The redox potential (Fig. 1b) initially decreased to -500 $\mathrm{mV}$ at PV 6, but increased to positive values by PV 10 and progressively returned to the control value of $200 \mathrm{mV}$. Similarly, the $\mathrm{pH}$ was initially influenced by the injection of alkaline CPS solution (pH 11.5), but progressively returned to near-neutral conditions by PV 50.

Sulfur leaching was very high immediately following injection, reaching $3,660 \mathrm{mg} / \mathrm{L}$ at PV 6 . It decreased to $70 \mathrm{mg} / \mathrm{L}$ by PV 12, $20 \mathrm{mg} / \mathrm{L}$ by PV 20 and reached background values by the end of the experiment. The effluent was also monitored using a sulfide-specific probe, which indicated that sulfide was present only during the initial PV following injection; by PV 10, it was below the detection limit $(0.003 \mathrm{mg} / \mathrm{L})$. Although the exact speciation of sulfur in the effluent was not determined, possibilities include thiosulfate $\left(\mathrm{S}_{2} \mathrm{O}_{3}{ }^{2-}\right)$, sulfite $\left(\mathrm{SO}_{3}{ }^{2-}\right)$ and sulfate $\left(\mathrm{SO}_{4}{ }^{2-}\right)$. Thiosulfate has been found to form preferentially as a result of CPS oxidation [11, 15]. Despite the high concentration of sulfur in the outflow, the overall amount leached $(\sim 210 \mathrm{mg})$ was very small compared to the amount added $(5,800 \mathrm{mg})$, which corresponds to $96.5 \%$ of sulfur retained in the soil.

The strongly reducing environment and elevated $\mathrm{pH}$ conditions created by CPS resulted in mobilization of metals, including $\mathrm{Cr}(\mathrm{III}), \mathrm{Pb}$ and $\mathrm{Ni}$ (Fig. S1). The dissolved metal front was quickly attenuated as the redox potential returned to positive values at PV 10. No substantial mobilization of Fe or Mn was observed at any time point (Fig. S1).

The post-mortem analyses of the column soil yielded non-detectable values of $\mathrm{Cr}(\mathrm{VI})$ in the solid using the conventional EPA methods 3060A and 7196. This method has been previously to be unreliable in CPS-treated solids [6], thus bulk and micro-XANES analyses were employed 
instead to assess the true extent of chromate reduction in the solid phase, as well as speciation of sulfur.

\subsection{Bulk XANES}

Figure 2 shows the percentage of $\mathrm{Cr}(\mathrm{VI})$ in the solid determined by bulk XANES as a function of time and CPS dosage. The majority of reduction at $2 \mathrm{X}$ stoichiometry occurred during the first 30 days of curing, with $\mathrm{Cr}(\mathrm{VI})$ decreasing from an average of $30 \%$ to $17 \%$ ( $<<0.001)$; this corresponds to absolute $\mathrm{Cr}(\mathrm{VI})$ concentrations of $4,000 \mathrm{mg} / \mathrm{kg}$ and $2,040 \mathrm{mg} / \mathrm{kg}$ for an average total $\mathrm{Cr}$ concentration of $12,000 \mathrm{mg} / \mathrm{kg}$ (Table 1). These results are in good agreement with $\mu X A N E S$ results reported by Chrysochoou et al. [6] for 60-day cured batch samples. No statistically significant differences $\left(\mathrm{p}_{1 \mathrm{M}-2 \mathrm{M}}=0.57, \mathrm{p}_{2 \mathrm{M}-3 \mathrm{M}}=0.2\right)$ were observed between subsequent data points, so that $\mathrm{Cr}(\mathrm{VI})$ reduction substantially slowed down or altogether stopped at 30 days. The redox potential remained, however, at $-500 \mathrm{mV}$ in all samples up to 90 days, given that they were closed to the atmosphere, and the $\mathrm{pH}$ was constant at 11 . When the stoichiometry of added CPS was increased from $2 \mathrm{X}$ to $8 \mathrm{X}$ at 30 days curing time, the $\mathrm{Cr}(\mathrm{VI})$ percentage decreased to $11 \%\left(\mathrm{p}_{2 \mathrm{X}-8 \mathrm{X}}=0.007\right)$, while the intermediate dosage of $4 \mathrm{X}$ did not yield a statistically significant difference in the $\mathrm{Cr}(\mathrm{VI})$ percentage $\left(\mathrm{p}_{2 \mathrm{x}-4 \mathrm{x}}=0.83\right)$. Similarly, the redox potential was at $-500 \mathrm{mV}$ and the $\mathrm{pH}$ at 11 for all samples tested.

The S XANES spectra of the cured samples and reference compounds are shown in Fig. 3, and the primary peak positions of the different oxidation states are summarized in Table 1. The reference compounds had similar features and peak positions to standard spectra reported elsewhere $[16,17]$. The spectrum of pure calcium polysulfide showed peaks at $2471.6 \mathrm{eV}$ and $2473.4 \mathrm{eV}$, which correspond to the absorption energies of sulfide and elemental sulfur, 
respectively. Similar results were reported by Vairavamurthy [17], who assigned the $2473.3 \mathrm{eV}$ peak to di- and polysulfidic sulfur. The oxidation states of the polysulfide ions are -2 at the end and 0 in the middle of the chain [18], so that the peak positions and formal oxidation states are in agreement. Two additional peaks were observed at 2479.8 and $2481.4 \mathrm{eV}$, which are similar to secondary peak positions of thiosulfate ( 2480 and $2481.6 \mathrm{eV}$ ). It is plausible that some thiosulfate is formed in the polysulfide solution upon exposure to the atmosphere. One difference that could distinguish the two compounds is that the height ratio of the two peaks in the CPS spectrum is 1.005 , while the respective ratio in the $\mathrm{Na}_{2} \mathrm{~S}_{2} \mathrm{O}_{3}$ spectrum is 1.23 ; this is likely because the zero oxidation state in the CPS chain contributes intensity to the $2480 \mathrm{eV}$, but not to the 2481.6 peak.

The spectra of the cured samples all had quite similar features. Attempts to fit the experimental spectra by linear combination of the standard compounds yielded poor results because of selfabsorption effects and because the physical state of the sulfur species in the samples was not identical to the standard spectra, which is required for accurate quantitative analysis of S XANES spectra [19]. Thus, we use qualitative observations to draw conclusions about $\mathrm{S}$ transformation in the soil.

Peaks were observed for all samples at 2473.3, 2480.0 and $2481.4 \mathrm{eV}$, and a few spectra had a shoulder at $2471.6 \mathrm{eV}$. This peak that indicates the presence of sulfide species (either as sulfide or polysulfide) was identified in samples cured for 0 and 7 days at $2 \mathrm{X}$ CPS dosage and in samples cured for 1 month at $4 \mathrm{X}$ and $8 \mathrm{X}$ stoichiometry. Thus, residual reductive capacity in the form of sulfide was observed at short curing times or high dosages. In contrast, longer curing times $(\geq 1 \mathrm{M})$ and lower dosages $(\leq 2 \mathrm{X})$ exhibited broadening of the $2473.3 \mathrm{eV}$ peak, which is characteristic of the elemental sulfur spectrum (Fig. 2b). The peaks at 2480.0 and $2481.4 \mathrm{eV}$ may 
be attributed to several species, including elemental S, polysulfide, thiosulfate and galena.

Galena has a characteristic peak at $2477.9 \mathrm{eV}$ that was not identified in any of the sample spectra and was thus excluded from further consideration. Polysulfides are only stable in solution at alkaline $\mathrm{pH}$, since their pka values are at 9.2 or higher [20]. The $\mathrm{pH}$ of the batch samples was maintained above 10 up to 1 month of curing and above 9 up to 3 months of curing at $2 \mathrm{X}$ stoichiometry, so that the presence of polysulfides is not implausible in any of the samples with peaks at $2471.6 \mathrm{eV}$. In the remaining samples, the spectrum appears to be a combination of elemental sulfur and thiosulfate. A broader peak at $2473.3 \mathrm{eV}$ indicates a higher amount of elemental sulfur, while a more pronounced peak at $2481.4 \mathrm{eV}$ indicates a higher concentration of thiosulfate. Using this criterion, it appears that the 1M-1X sample had a higher thiosulfate concentration, while $1 \mathrm{M}-2 \mathrm{X}$ had some thiosulfate but more elemental sulfur, and higher dosages had residual sulfide/polysulfide that dominated the spectra. The spectra obtained at $2 \mathrm{X}$ dosage up to 3 months of curing showed that thiosulfate was present up to 90 days, with the sulfur peak at 2480.0 being slightly more pronounced at 90 days, indicating that additional reactions occurred, albeit at a slow pace.

\subsection{Micro-X-Ray Analyses}

Three $\mu$ XRF maps were acquired for the column samples, with a total area of $7.1 \mathrm{~mm}^{2}$ in the untreated sample and $8.8 \mathrm{~mm}^{2}$ in the treated sample. The tricolor $\mathrm{Cr}(\mathrm{VI})-\mathrm{Si}-\mathrm{Fe}$ maps are shown in Fig. S2, and the $\mathrm{Cr}(\mathrm{VI})-\mathrm{Pb}-\mathrm{S}$ maps for the column and batch samples are shown in Fig. 4.

$\mathrm{Cr}(\mathrm{VI})$ was primarily present as small grains in the interstitial spaces between larger quartz and feldspar grains and associated with $\mathrm{Pb}$. The bulk measurements of the two compounds indicate that up to $66 \%$ of $\mathrm{Cr}(\mathrm{VI})$ may be bound as $\mathrm{PbCrO}_{4}$. The correlation coefficient between the 
counts of the two elements was 0.57 , which provides an excellent agreement between the two measurements. $\mathrm{Cr}(\mathrm{VI})$ association with Fe was observed in a few grains in the untreated sample (Fig. S2). While the overall correlation coefficient between $\mathrm{Fe}$ and $\mathrm{Cr}(\mathrm{VI})$ counts was very low for the entire area $\left(\mathrm{R}^{2}=0.08\right)$, it was 0.94 when these grains were isolated. This indicates that some of the $\mathrm{Cr}(\mathrm{VI})$ was sorbed on Fe oxide coatings, a mechanism that is plausible at $\mathrm{pH} 5.5$ of the untreated soil. The correlation coefficient for $\mathrm{Pb}$ and $\mathrm{Cr}(\mathrm{VI})$ counts increased from 0.57 in the untreated areas to 0.92 in the treated area, indicating that $\mathrm{Cr}(\mathrm{VI})$ that was not present as $\mathrm{PbCrO}_{4}$ was preferentially reduced upon CPS addition. This is corroborated by the fact that areas with low $\mathrm{Cr}(\mathrm{VI})$ counts were preferentially eliminated in the treated sample. The bulk measurements indicate that approximately $1 / 3$ of the initial $\mathrm{Cr}(\mathrm{VI})$ was not bound by $\mathrm{Pb}$ and more available for reduction. The batch XANES analyses further showed that this more available $\mathrm{Cr}(\mathrm{VI})$ fraction was reduced by 30 days curing, and that the remaining fraction that was almost exclusive present as $\mathrm{PbCrO}_{4}$ was recalcitrant to treatment, despite the persistence of highly reducing environment $(-500 \mathrm{mV})$.

The $\mu$ XRF maps (Fig. 4c and Fig. 4d) show that sulfur was present in two main forms: concentrated in bright green spots and diffuse within the matrix, where it was associated with other elements, particularly $\mathrm{Pb}$ and $\mathrm{Cr}$. Given that $\mathrm{Pb}$ presented high correlation with $\mathrm{Cr}(\mathrm{VI})$ in the treated maps, we isolated the areas with high $\mathrm{S}-\mathrm{Cr}$ and $\mathrm{S}-\mathrm{Pb}$ correlations, the tricolor maps of which are shown in Fig. 5. Six points were selected in these areas (Fig. 5) and subjected to $\mu$ XANES analysis, the spectra of which are shown in Fig. 3d.

Points P0 and P1 were mostly green (Fig. 5a and Fig. 5b), which corresponds to S in the tricolor maps, and the respective $\mu$ XANES spectra closely matched elemental sulfur. Thus, it is 
concluded that the bright green areas in Fig. $4 \mathrm{~d}$ correspond to pure elemental sulfur, produced by the reaction of (poly)sulfide and chromate, as predicted by redox reaction (1).

Figure 5a indicates that even when $\mathrm{Pb}$ was in close proximity, there was limited tendency for sulfide to be scavenged and form galena $(\mathrm{PbS})$, but remained as free $\mathrm{Pb}$ (more likely $\mathrm{Pb}$ carbonate or oxide) after chromate was released from $\mathrm{PbCrO}_{4}$, which was observed to bind practically all available $\mathrm{Pb}$ in the untreated sample (Fig. 4a and Fig. 4b). The area around $\mathrm{P} 2$ was similar, and the $\mu$ XANES spectrum was quite close to elemental sulfur, but it clearly included another species, most likely thiosulfate. Points $\mathrm{P} 3$ and $\mathrm{P} 4$ show even more prominent features similar to thiosulfate in the region around $2480 \mathrm{eV}$. The $\mu \mathrm{XRF}$ map indicates that the corresponding points consist primarily of $\mathrm{S}$ (green) with some $\mathrm{Pb}$ (blue) as well.

The area with the most prominent association of $\mathrm{Pb}$ and $\mathrm{S}$ was the grain around P6 (Fig. 5f). The $\mu$ XANES spectrum indicated that $\mathrm{S}$ was present primarily as thiosulfate, which forms $\mathrm{PbS}_{2} \mathrm{O}_{3}$ with a solubility of $300 \mathrm{mg} / \mathrm{L}$ at $15{ }^{\circ} \mathrm{C}_{2} \mathrm{O}$ [21]. While the solubility of this compound is relatively high, the high sulfur concentrations in the column effluents (Fig. 1d) and the high ability of S to remain in the solid may be conducive to its stability, especially at short time frames. Its continuous dissolution in water may in fact be favorable towards additional reduction of slowly released chromate. Figure 5e supports this notion, given that the $\mu$ XANES shows a clear thiosulfate spectrum, while the $\mu \mathrm{XRF}$ map indicates the co-existence of all three elements, with $\mathrm{Cr}(\mathrm{VI})$ contributing the majority of the observed counts (as indicated by the pink color). A large grain with high $\mathrm{Pb}-\mathrm{S}$ correlation was also observed in the column sample (Fig. 4e), however no XANES spectrum is available for that area. 
The column contained approximately $3,300 \mathrm{mg}$ of $\mathrm{Pb}(13,200 \mathrm{mg} / \mathrm{kg}$ in $250 \mathrm{~g}$ soil $)$ or approximately $16 \mathrm{mmol}$, which could bind up to $32 \mathrm{mmol}$ or $1,024 \mathrm{mg}$ of $\mathrm{S}$ as $\mathrm{PbS}_{2} \mathrm{O}_{3}$. This is approximately $20 \%$ of the total S that was retained in the soil column $(5,600 \mathrm{mg})$. Thiosulfate does not form any other insoluble precipitates in soil environments, so that the only other known retention mechanism is sorption to iron oxides, which are positively charged at $\mathrm{pH}<8-9$ [22]. Even though no crystalline iron oxides were identified in the soil matrix by XRD, the high Fe concentration in the soil indicates that amorphous Fe oxyhydroxides are most likely present. Given that polysulfides create an alkaline environment, a sorption mechanism is likely not favored for anionic thiosulfate at short curing times; however, as the $\mathrm{pH}$ decreased below 8 after $20 \mathrm{PV}$ in the column experiments, sorption may enhance thiosulfate retention in the soil.

\subsection{Implications for treatment}

The XANES and micro-XANES results clearly indicated that there are two main sulfur species that are present in CPS-treated soil long-term (days and months after treatment): elemental sulfur, which is the main oxidation product by reaction with chromate, and thiosulfate. Both were present under strongly reductive conditions $(-500 \mathrm{mV})$ in the absence of oxygen. While thiosulfate is a reductant for $\mathrm{Cr}(\mathrm{VI})$, it requires strongly acidic conditions for effective reduction; above $\mathrm{pH}$ 2.5, the kinetic rate of reduction becomes almost zero [23]. IETEG [2] reported no $\mathrm{Cr}(\mathrm{VI})$ reduction by $\mathrm{NaS}_{2} \mathrm{O}_{3}$ at neutral $\mathrm{pH}$ conditions and $3 \mathrm{hrs}$ of reaction time. Thus, it is considered unlikely that direct reduction of chromate by thiosulfate is a viable long-term reductive mechanism in CPS treated soil.

The production of naturally occurring Fe(II) in soils treated with CPS and sodium dithionite has been previously reported $[24,25]$. The mobilization of iron in the column outflow in the initial 
PVs after CPS injection (Fig. S1) is indicative of reduction of Fe bound in $\mathrm{Fe}(\mathrm{III})$-oxides in the soils, however, the long-term fate of Fe in the column is unknown. The presence of thiosulfate can aid the persistence of $\mathrm{Fe}(\mathrm{II})$ that remains sorbed on iron oxides at the alkaline $\mathrm{pH}$ of the soil via two mechanisms: direct reduction of Fe(III), or scavenging of oxidants, including any dissolved oxygen. Su and Ludwig [26] observed retardation in the rate of Fe(II) oxidation in the presence of dithionite and attributed this phenomenon to oxygen scavenging by dithionite and sulfite, both of which are used in the petroleum industry to strip oxygen from water [27, 28]. Thiosulfate has been shown to react with Fe(III)-bearing phyllosilicates to produce Fe(II) and $\mathrm{S}_{4} \mathrm{O}_{6}{ }^{2-}$, even though it is a less potent reductant compared to sulfide and dithionite [29]. In acidic conditions, thiosulfate decomposes to sulfite and elemental sulfur, while it is stable in neutral environments [30]. Thiosulfate will react with oxygen only in the presence of a mineral catalyst, such as pyrite $\left(\mathrm{FeS}_{2}\right)$ and sphalerite $(\mathrm{ZnS})$ doped with transition metals [31, 32]. Given the apparent absence of sulfidic minerals, oxygen scavenging is likely not an important mechanism; persistence of $\mathrm{Fe}(\mathrm{II})$ viable mechanism to sustain long term reductive environment. If this conclusion holds, the presence of iron in the system can enhance CPS performance. Additional studies on the fate of iron in the system are required to investigate this hypothesis.

\section{Conclusions}

Treatment of $\mathrm{Cr}(\mathrm{VI})$-contaminated soil with a stoichiometric dosage of CPS indicated that the majority of sulfur (96.5\%) was retained within the soil column for $45 \mathrm{PV}$, which corresponded to approximately 3.5 months of groundwater flow at the site, with a velocity of $0.03 \mathrm{~m} / \mathrm{d}$. Sulfide and low redox potential were short lived in the column effluent, with the redox potential increasing from $-460 \mathrm{mV}$ to $+130 \mathrm{mV}$ after $3 \mathrm{PV}$ of simulated groundwater flow. Chromium(VI) was not detected in the column effluent at any time point after CPS injection, even though it was 
established from previous studies that it is mostly bound in the soil as $\mathrm{PbCrO}_{4}$ and thus leaches slowly from the solid matrix into solution.

Bulk and micro-XANES analyses confirmed that $\mathrm{Cr}(\mathrm{VI})$ that was not present as $\mathrm{PbCrO} 4$ was completely reduced, while $\mathrm{PbCrO}_{4}$ was recalcitrant to treatment, despite the persistence of a reducing environment as indicated by the redox potential. The soil maintained a reducing capacity even after sulfide was no longer detected in solution. Both bulk and micro-XANES analyses indicated that sulfur speciation in both the batch and column solids was a combination of elemental sulfur and thiosulfate. The micro-XRF analyses indicated that elemental sulfur precipitated as larger discrete particles, while thiosulfate was observed to be diffuse within the soil grains, associated in some cases with $\mathrm{Pb}$. It is concluded that $\mathrm{PbS}_{2} \mathrm{O}_{3}$ may have bound up to $20 \%$ of sulfur within the soil column. Sorption of thiosulfate to abundant iron oxides present is also a likely retention mechanism in the soil below $\mathrm{pH} 8$. Given that thiosulfate cannot reduce chromate but can reduce $\mathrm{Fe}(\mathrm{III})$ even when bound in minerals under neutral $\mathrm{pH}$ conditions, it is hypothesized that long term reduction of $\mathrm{Cr}(\mathrm{VI})$ in CPS treated soil may be enhanced by the presence of Fe oxides.

\section{Acknowledgments.}

This work was supported by National Chromium Inc. Sirine Fakra and Matthew A. Marcus of LBNL assisted with $\mu$ XAS data acquisition and analysis. ALS-LBNL operations are supported by the Director, Office of Science, Office of Basic Energy Sciences, U.S. Department of Energy under contract number DE-AC02-05CH11231. Portions of this research were carried out at the Stanford Synchrotron Radiation Lightsource, a directorate of SLAC National Accelerator 


\author{
Laboratory and an Office of Science User Facility operated for the U.S. Department of Energy \\ Office of Science by Stanford University.
}

\title{
References
}

1. USEPA (United States Environmental Protection Agency), 2000. In situ treatment of soil and groundwater contaminated with chromium: Technical Resource Guide, EPA 625/R-00/004.

2. IETEG (Independent Environmental Technical Evaluation Group), 2005. Chromium (VI) Handbook. Boca Raton: CRC Press.

3. S.W. Petersen, K.A. Hedquist, Treatability test report for calcium polysulfide in the 100-K area, (2006) DOE/RL-2006-17.

4. P. Storch, A. Messer, D. Palmer, R. Pyrih, Pilot test for in situ geochemical fixation of chromium (VI) using calcium polysulfide, Proceedings of the Third International Conference on Remediation of Chlorinated and Recalcitrant Compounds, Battelle Press, Monterey, CA, 2002.

5. R.J.F. Bewley, S. Clarke, Field application of calcium polysulphide for ex situ treatment of soils contaminated with chromite ore processing residue, Land. Contam. Reclam. 18 (2010) 1-12.

6. M. Chrysochoou, D.R. Ferreira, C.P. Johnston, Calcium polysulfide treatment of Chromate contaminated soil, J. Haz. Mat. 179 (2010) 650-657.

7. M. Wazne, S.C. Jagupilla, D.H. Moon, S.C. Jagupilla, C. Christodoulatos, M.G. Kim, Assessment of calcium polysulfide for the remediation of hexavalent chromium in chromite ore processing residue (COPR), J. Haz. Mat. 143 (2007) 620-628.

8. J.M. Tinjum, C.H. Benson, T.B. Edil, Treatment of CrVI in COPR using ferrous sulfate-sulfuric acid or cationic polysulfides, J. Geotech. Geoenviron. 134 (2008) 1791-1803. 
9. USDOE (United States Department of Energy), 2004. Hanford site. Evaluation of Amendments for mending the ISRM barrier. Technical Assistance Project \#33, Final Technical Solutions Report.

10. M. Wazne, P. Papazoglou, M. Papastavrou, X. Meng, D. Dermatas, C. Christodoulatos, Remediation of Chromite Ore Processing Residue by Chemical Reductants, Conference Proceedings In situ and one site Bioremediation Symposium, Battelle, Columbus, Ohio, 2005.

11. M. Chrysochoou, A. Ting, A kinetic study of Chromate reduction by calcium polysulfide, Sci. Tot. Environ. 409 (2011) 4072-4077.

12. M. Chrysochoou, C. Johnston, G. Dahal, A comparative evaluation of Chromate treatment in contaminated soil by calcium polysulfide and nanoscale zero valent iron, J. Haz. Mat. 201-202 (2012) 33-42.

13. M. Avrahami, R.M. Golding, The oxidation of the sulphide ion at very low concentrations in aqueous solutions, J. Chem. Soc. A. 0 (1968); 647-651.

14. M.A. Marcus, X-ray photon-in/photon-out methods for chemical imaging, Trends Anal. Chem. 29 (2010) 508-517.

15. W. Kleinjan, A. Keizer, A. Janssen, Kinetics of the chemical oxidation of polysulfide anions in aqueous solution, Water Res. 39 (2005) 4093-4100.

16. F. Jalilehvand, Sulfur: Not a "silent" element any more, Chem. Soc. Rev. 35 (2006) 1256-1268.

17. A. Vairavamurthy, Using X-ray absorption to probe sulfur oxidation states in complex molecules, Spectrochim. Acta Part A 54 (1998) 2009-2017.

18. A.J. Kamyshny, A. Goifman, J. Gun, D. Rizkov, L. Ovadia, Equilibrium distribution of polysulfide ions in aqueous solutions at $25^{\circ} \mathrm{C}$ : A new approach for the study of polysulfides' equilibria, Environ. Sci. Technol. 38 (2004) 6633-6644.

19. G. Almkvist, K. Boye, I. Persson, K-edge XANES analysis of sulfur compounds: An investigation of the relative intensities using internal calibration, J. Synchrotron. Radiat. 17 (2010) 683-688.

20. G. Maronny, Constantes de dissociation de l'hydrogene sulfure, Electrochimica Acta 1 (1959) 58-69. 
21. HSDB (Hazardous Substances Databank) URL: http://toxnet.nlm.nih.gov/cgi-bin/sis/search [Accessed 15 September 2013]

22. G. Sposito, The chemistry of soils. 1 ed., Oxford University Press, New York, 1989.

23. I. Baldea, G. Niac, The Reaction between Chromate and Thiosulfate. 11. The Kinetics of Tetrathionate, Formation. Inorg. Chem. 9 (1970) 110-114.

24. M. Ridley, Summary report on the subsurface chromium reduction treatment test at riverbank army ammunitions plant, Lawrence Livermore National Laboratory, (2007) UCRL-TR-231326.

25. L. Zhong, N. Qafoku, J. Szecsody, J.E. Dresel, Z. Zhang, Foam Delivery of Calcium Polysulfide to the Vadose Zone for Chromium(VI) Immobilization: A Laboratory Evaluation, Vadose Zone J. 8 (2009) 976985.

26. C. Su, R.D. Ludwig, Treatment of Hexavalent Chromium in Chromite Ore Processing Solid Waste Using a Mixed Reductant Solution of Ferrous Sulfate and Sodium Dithionite, Environ. Sci. Technol. 39 (2005) 6208-6216.

27. E. S. Jr. Snavely, Chemical removal of oxygen from natural waters, J. Petrol. Technol. 23 (1971) 443446.

28. B. L. Knight, Reservoir stability of polymer solutions, J. Petrol. Technol. 25 (1973) 618-626.

29. J.W. Stucki, G.W. Bailey, H. Gan, Oxidation-reduction mechanisms in iron-bearing phyllosilicates, Appl. Clay Sci. 10 (1996) 417-430.

30. D. Lyons, G. Nickless, The lower oxy-acids of sulfur, in: G. Nickless (Ed.), Inorganic Sulphur Chemistry, Elsevier, Amsterdam, 1968, pp. 509-532.

31. Y. Xu, M. Schoonen, R. Strongin, Thiosulfate oxidation: Catalysis of synthetic sphalerite doped with transition metals, Geochim. Cosmochim. Acta 60 (1996) 4701-4710.

32. Y. Xu, M. Schoonen, The stability of thiosulfate in the presence of pyrite in low-temperature aqueous solutions, Geochim. Cosmochim. Acta 59 (1995) 4605-4622. 
33. ESRF (European Synchrotron Radiation Facility) ID21 Sulfur XANES datatase. URL:

http://www.esrf.eu/UsersAndScience/Experiments/Imaging/ID21/php [Accessed 15 September 2013] 
Table 1. Peak positions in S K edge spectra of pure S compounds

\begin{tabular}{llll}
\hline Compound & Oxidation & Main peak (eV) & Additional peaks (eV) \\
& State & & \\
\hline $\mathbf{F e S}_{\mathbf{2}}$ & -2 & 2471.5 & 2482.0 \\
$\mathbf{P b S}^{\mathbf{a}}$ & -2 & 2472.7 & $2479.8,2481.4$ \\
$\mathbf{C P S}$ & $-2,0$ & $2471.6,2473.4$ & \\
$\mathbf{S}_{\mathbf{8}}$ & 0 & 2473.2 & $2480.0,2481.6$ \\
$\mathbf{N a}_{2} \mathbf{S}_{\mathbf{2}} \mathbf{O}_{3}$ & $-2,+6$ & 2472.6 & $2481.0,2482.6$ \\
$\mathbf{N a}_{2} \mathbf{S O}_{3}$ & +4 & 2479.0 & \\
$\mathbf{N a}_{\mathbf{2}} \mathbf{S O}_{\mathbf{4}}$ & +6 & 2483.4 & \\
\hline
\end{tabular}

${ }^{\mathrm{a} S p e c t r u m ~ o b t a i n e d ~ f r o m ~ E S R F ~ I D 21 ~ S u l f u r ~ X A N E S ~ d a t a t a s e ~(E S R F, ~ 2013) ~}$ 

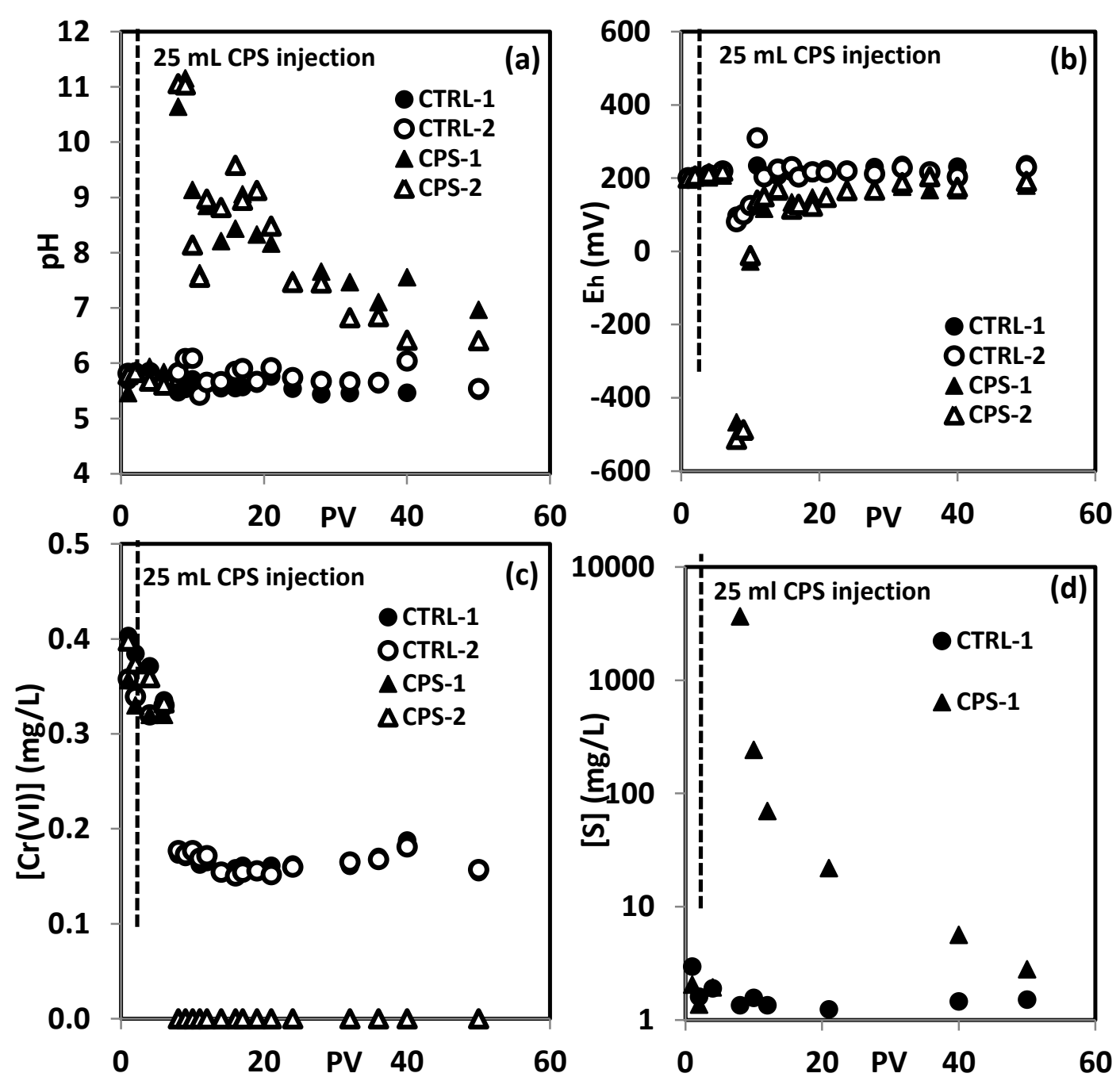
Figure 2
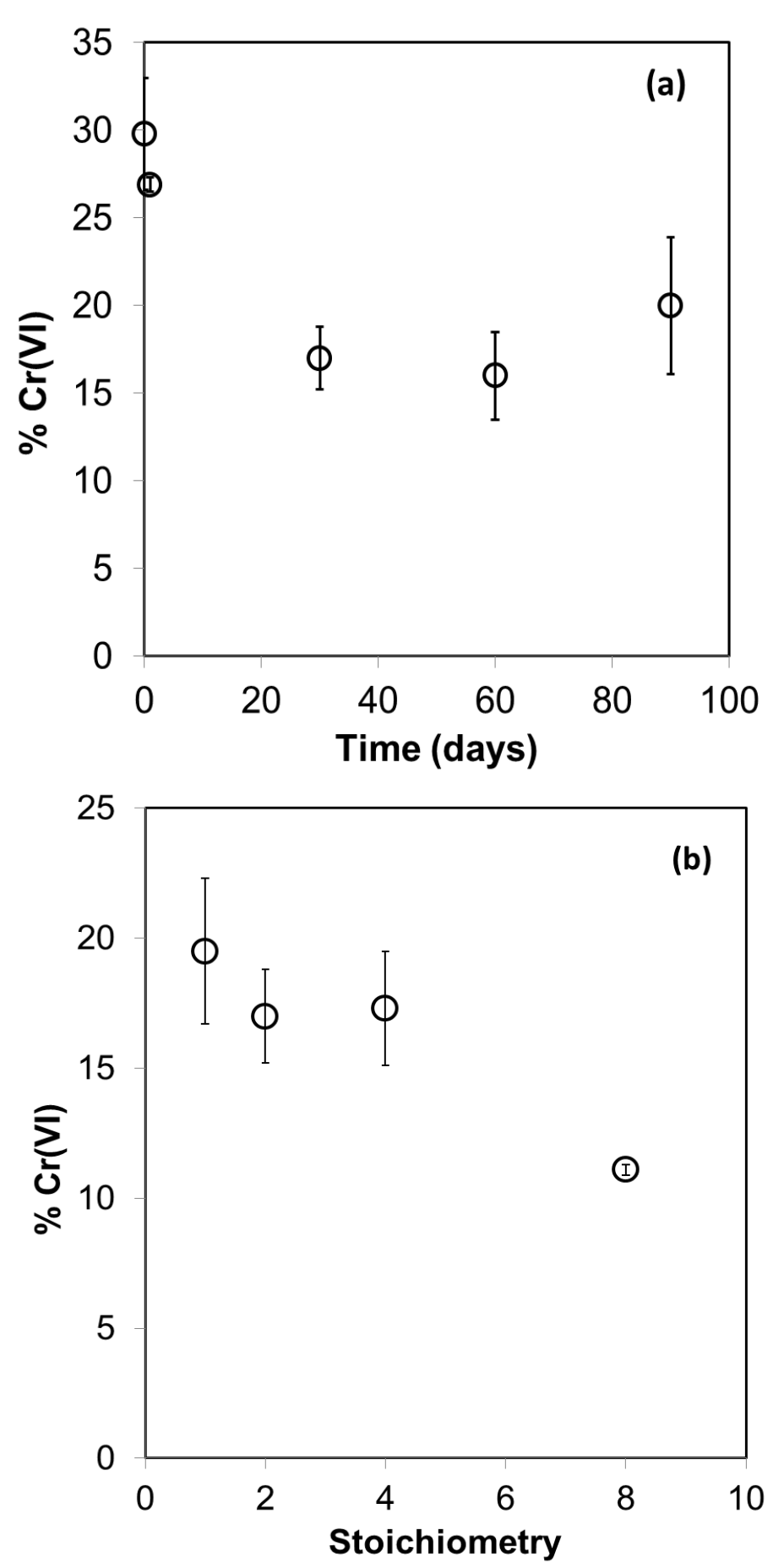

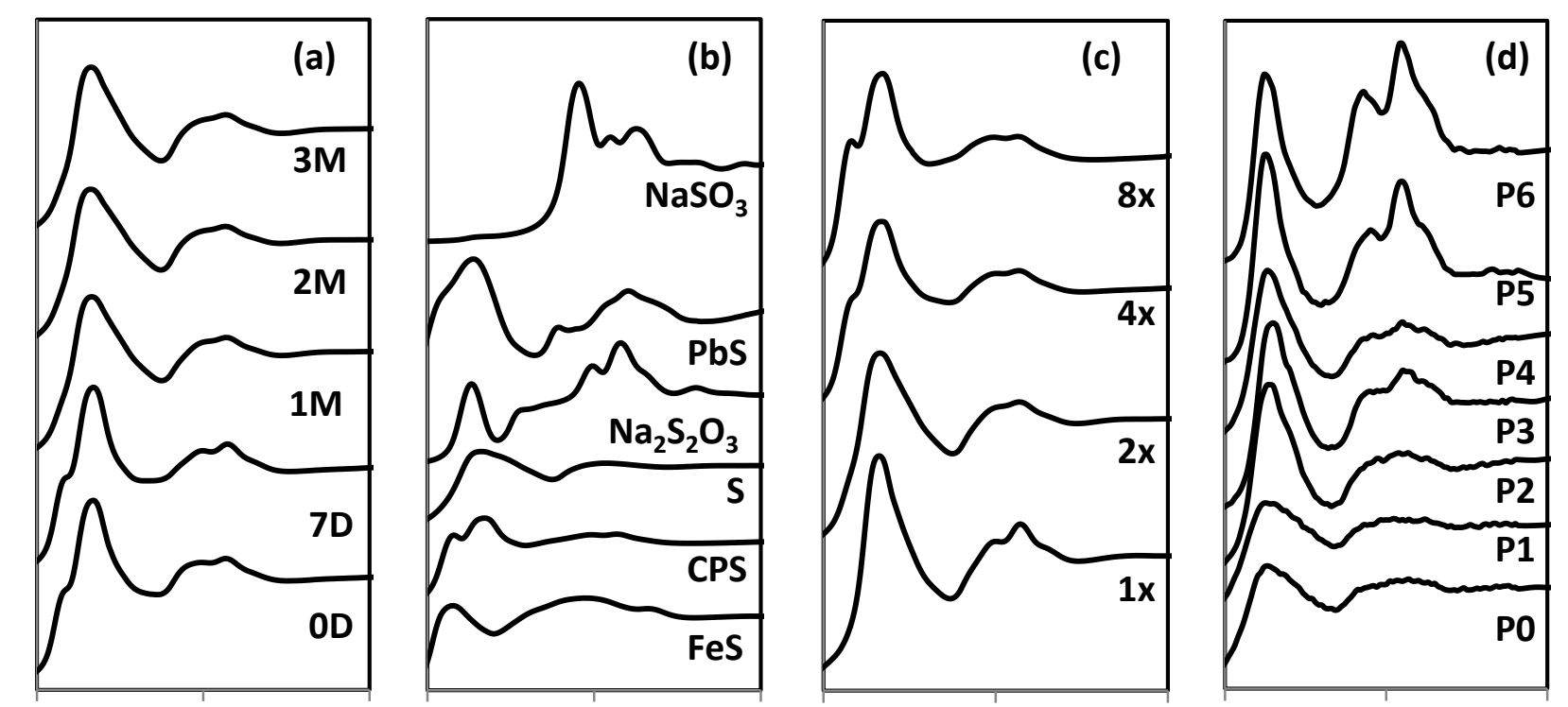

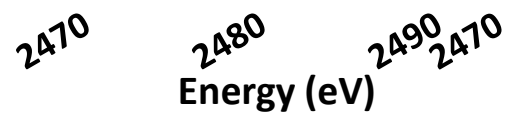

$\operatorname{Energy}^{20 \mathrm{eV})}{ }^{209^{290}}{ }^{4 \times 10}$

Energy (eV) $202^{2400}$

Energy $^{22^{8.0}}{ }^{22)^{290}}$ 


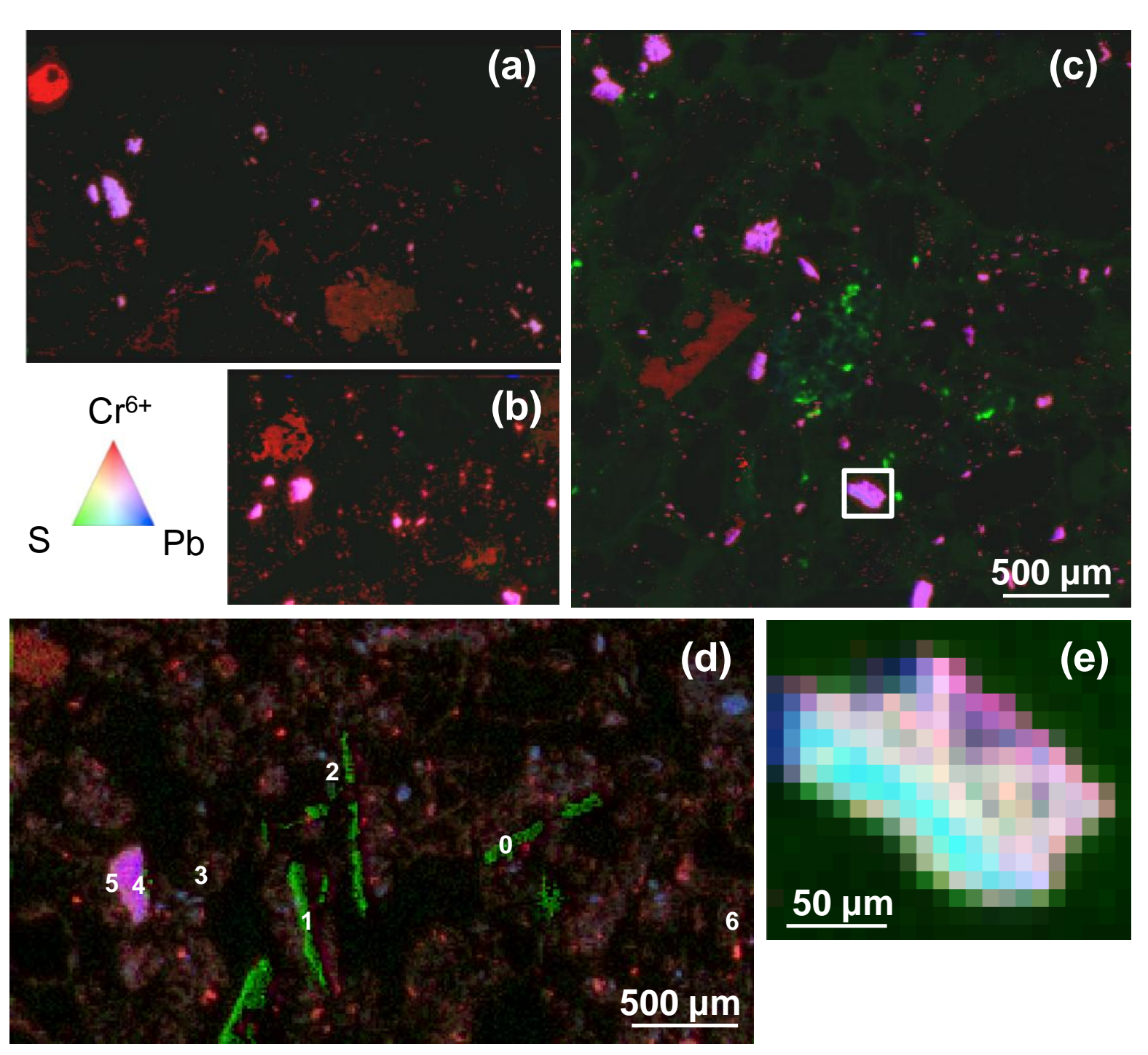


